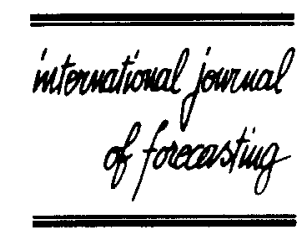

\title{
Forecasting and seasonality
}

\author{
Jan G. De Gooijer ${ }^{a, *}$, Philip Hans Franses ${ }^{\mathrm{b}}$ \\ 'Department of Economic Statistics, University of Amsterdam, Roetersstraat 11, 1018 WB Amsterdam, Netherlands \\ ${ }^{\mathrm{h}}$ Econometric Institute and Rotterdam Institute for Business Economic Studies, Erasmus University Rotterdam. P.O. Box 1738. \\ 3000 DR Rotterdam. Netherlands
}

\section{Introduction}

Seasonal fluctuations account for a major part in the variation in the growth rates of most quarterly and monthly business and economic time series. In order to make inferences on the nature of business cycles and long-run growth, the 'traditional' approach is to remove the seasonal component of a series through the use of deterministic dummies, seasonal differencing, or by the use of seasonal adjustment methods like the Census Bureau's X-12ARIMA filter. However, it is sometimes argued that it can be appropriate to study seasonal patterns in their own right since they may convey information on the behaviour of economic agents who face changing patterns when making plans and forming expectations. Hence, although seasonally adjusted data may sometimes be useful, it is typically recommended to use seasonally unadjusted data (if these are available). Additionally, several recent empirical studies have shown that many seasonal adjustment methods lead to severely distorted data, in the sense that key properties as trends, business cycles, and nonlinearities are affected by seasonal adjustment. Surveys on these issues appear in Ghysels (1994); Hylleberg (1994); Miron (1996) and Franses (1996), among others. These studies have motivated research topics as testing for seasonal unit

\footnotetext{
*Corresponding author. Tel.: + 31-20-525 4244; fax: + 31-20525 4349: e-mail: jandeg@fee.uva.nl
}

roots, modelling seasonal and business cycles, and periodic models. The purpose of this special issue is to explore some of these topics as they relate to forecasting with models that explicitly characterize seasonality.

\section{Overview}

Roughly speaking the two most dominant classes of models for trending seasonal time series are (i) models with one or more seasonal unit roots; and (ii) periodic models, possibly with unit roots. These two classes address the main properties of many economic data, i.e. seasonal variation is quite substantial (once the data are detrended) and seasonality tends to change over time. In the form of periodic integration, the periodic unit roots model can also describe time series with seasonality being dependent on the trend and/or the business cycle. The seasonal unit roots models assume that seasonal variation appears in specific forms of the lag structure, whereas imposing unit roots leads to various degrees of changing seasonality. Periodic models assume that seasonal variation can be described by allowing the lag structures to take different forms in different seasons. The ten papers published here' deal with one or the

\footnotetext{
'Several of these papers were presented at the 14th International Symposium on Forecasting in Toronto, Canada, 1995.
} 
other model class, where some treat univariate models and other multivariate models. As such they provide a good overview of the most recent state-ofthe-art of research in this area.

The first three articles (Taylor, King and Kulendran, and Hylleberg and Pagan) deal with either applications or extensions of the seasonal unit roots model. Taylor discusses lag selection in a test procedure for seasonal unit roots. This is a far from a trivial issue, with possible effects on forecasting. King and Kulendran evaluate several models, including the scasonal unit roots model, in forecasting quarterly tourist arrivals into Australia from separate parts of the world. Their main conclusion is that relative to time series models, the forecasting performance of the seasonal unit roots model is poor. This may be due to the lack of power of some unit roots tests. Hylleberg and Pagan introduce the socalled evolving seasonals model, which is an important extension to the harmonic regression model of seasonality proposed in the sixties. In the evolving seasonals model the seasonal factors vary with frequency, represented by autoregressive processes. Hylleberg and Pagan show that simple transformations of the data enable one to isolate the coefficients attached to these seasonal factors. This result will motivate further research into a much broader set of tests for seasonal integration than are currently used in practice.

The next two papers deal with the stability of seasonal unit roots models to structural breaks. Clements and Hendry study the effects of overspecifying the number of seasonal unit roots for out-of-sample forecasting. Based on two empirical examples, they conclude that imposing unit roots at all frequencies results in at least as good a forecasting performance as imposing a smaller number of roots suggested by a test for seasonal unit roots. Furthermore, they discuss appropriate measures of forecasting accuracy for seasonal time series. Paap, Franses and Hoek use empirical and simulation examples to show that neglected seasonal mean shifts can substantially deteriorate forecasting performance of univariate autoregressive processes.

The following two papers are concerned with multivariate unit roots models, i.e., the so-called seasonal cointegration models. Reimers uses simulations to show that imposing appropriate parameter restrictions in a bivariate seasonal vector autoregressive process can lead to better forecasts, although substantial improvement tends to emerge only for longer forecasting horizons. Lee and Siklos show that a seasonal cointegration model leads to more useful inference on the money-income relationship than does a cointegration model for seasonally adjusted data. In fact, these authors show that important information is lost when using adjusted data.

The last three articles raise issues related to the forecasting performance of the class of periodic models. Using a set of seventeen UK quarterly macroeconomic time series Novales and Flores investigate the properties of these models for out-ofsample forecasting. They conclude that constrained periodic models can have a much better forecasting performance than non-periodic models. Wells, in a similar vein, focuses on quarterly US macroeconomic data. He shows that measures of persistence differ across model assumptions. Finally, Herwartz considers quarterly measured consumption-income data from the UK, Sweden, Germany, and Japan. His results indicate that the ex-ante forecasting performance of non-periodic models is not always improved by allowing for periodic variation in the central parameters of a bivariate error-correction model for the consumption equation.

\section{Concluding remarks}

The problems with seasonally adjusted economic data, and the theoretical reasons for using data that include seasonal fluctuations have both led to a revival of interest in seasonal modelling techniques. Much of the work in this area has been concerned with developing tests for seasonal unit roots and tests for periodic variation. In contrast, relatively few studies have explored the genuine out-of-sample forecast performance of models with seasonal unit roots and models with periodically varying parameters. Clearly, the ten papers published in this issue address this interesting problem in quite some detail. We believe that these papers will be valuable to those involved in forecasting seasonal business and economic time series, and we hope that they will stimulate further research in this fascinating area. 


\section{Acknowledgments}

This special issue has greatly benefited from the assistance of many individuals for serving as referees for papers submitted for this issue. In alphabetical order, the referees are: Tilak Abeysinghe (Singapore); Kevin Albertson (UK); William Bell (USA); Peter Boswijk (The Netherlands); Joerg Breitung (Germany); Chris Chatfield (UK); Andrew Clare (UK); Neil Ericsson (USA); Robert Fildes (UK); Clive Granger (USA); Bruce Hansen (USA); Andrew Harvey (UK); Helmut Herwartz (Germany); Steven Hillmer (USA); Svend Hylleberg (Denmark); Genshiro Kitagawa (Japan); Gary Koop (UK); ChunMing Kuan (USA); Robert Kunst (Austria); Michael McAleer (Australia); Brendan McCabe (Canada); Marius Ooms (The Netherlands); Denise Osborn (UK); Adrian Pagan (Australia); Richard Paap (The Netherlands); Danny Pfeffermann (Israel); Zacharias Psaradakis (UK); James Ramsey (USA); Hans-Eggert Reimers (Germany); Pierre Siklos (Canada); Jeremy Smith (UK); Norman Swanson (USA); Robert Taylor (UK); Aldo Vecchia (USA); Stephen Witt (UK). We are very grateful for their generous help. Finally, we wish to thank the Editor-in-Chief, Robert Fildes, for allowing us to put this issue together.

\section{References}

Franses, P.H., 1996. Recent advances in modelling seasonality. Journal of Economic Surveys 10, 299-345.

Ghysels, E., 1994, On the economics and econometrics of seasonality. In: Sims, C.A. (Ed.), Advances in Econometrics, Sixth World Congress of the Econometric Society. Cambridge University Press, Cambridge.

Hylleberg, S., 1994. Modelling seasonal variation. In: Hargreaves, C.P. (Ed.), Nonstationary Time Series Analysis and Cointegration, Oxford University Press, Oxford.

Miron, J.A., 1996. The Economics of Seasonal Cycles. MIT Press, Cambridge USA.

Biographies: Jan G. DE GOOIJER is Professor of Quantitative Methods and Chairman of the Department of Economic Statistics at the University of Amsterdam, The Netherlands. He has published widely in the areas of forecasting, time-series analysis, econometrics and statistics.

Philip Hans FRANSES is Associate Professor in Econometrics at the Econometric Institute for Business Economic Studies, both of the Erasmus University Rotterdam. His research interests include modelling and forecasting seasonal time series. On this topic, he has published in various journals and in Periodicity and Stochastic Trends in Economic Time Series (Oxford University Press, Oxford). 